\title{
Os irmãos nas novas configurações familiares
}

\author{
Siblings in the new family configurations
}

Caroline Rubin Rossato Pereira ${ }^{[0],}$ Dorian Mônica Arpini ${ }^{[b]}$

\footnotetext{
${ }^{[a]}$ Mestre e Doutoranda em Psicologia do Desenvolvimento pela Universidade Federal do Rio Grande do Sul (UFRGS), psicóloga da Pró-Reitoria de Assuntos Estudantis da Universidade Federal de Santa Maria/RS (UFSM), professora do curso de Psicologia da Universidade Luterana do Brasil (ULBRA), Câmpus Santa Maria, RS-Brasil, e-mail: carolinerrp@gmail.com

${ }^{[b]}$ Mestre em Educação Brasileira pela Universidade Federal de Santa Maria (UFSM), Doutora em Psicologia Social pela Pontifícia Universidade Católica de São Paulo (PUCSP), professora associada do Departamento de Psicologia da Universidade Federal de Santa Maria - RS (UFSM), Santa Maria, RS - Brasil.
}

Recebido: 26/04/2010 Received: 04/26/2010

Aprovado: $29 / 10 / 2010$ Approved: 10/29/2010

\section{Resumo}

Apesar do pouco investimento em estudos no âmbito da relação entre irmãos, este é um tema complexo e rico, abarcando diversas interações em seu desenvolvimento. Com as intensas transformações no âmbito das configurações familiares, acentuadas com o incremento nas taxas de divórcio a partir da década de 1990, a relação entre irmãos, assim como toda a estrutura familiar, ganhou em complexidade. Neste contexto, os laços que unem os membros familiares estariam caminhando para uma menor exigência de consanguinidade em nome de um incremento das relações por meio de laços afetivos de apoio mútuo. A partir desta perspectiva, o presente estudo visou a uma aproximação do universo dos irmãos nas novas configurações familiares a começar do olhar dos filhos adolescentes. Participaram da pesquisa seis adolescentes com idades entre 15 e 18 anos que viviam em famílias monoparentais ou reconstituídas e possuíam meios-irmãos e/ou irmãos políticos/circunstanciais. A análise de conteúdo qualitativa das entrevistas indicou a relevância do convívio próximo entre os irmãos para o sentimento de fratria. Além disso, o relacionamento estabelecido com o progenitor comum ou o/a padrasto/madrasta foi apontado pelos adolescentes como importante para o reconhecimento e a qualidade do relacionamento fraterno. 0 vínculo fraterno seria delimitado, em última instância, pelas ligações afetivas estabelecidas entre os membros da família, sendo necessários, para tanto, o convívio, o apoio mútuo, a troca afetiva.

Palavras-chave: Irmãos. Família recasada. Família monoparental.

\section{Abstract}

Despite the few investments in studies on sibling's relationships, this is a complex and rich theme, which involves many interactions throughout its development. With the intense changes in family configurations, marked by the increase in divorce rates from the 90s decade, siblings' relationships and the whole family structure have been added in complexity. Within this context, the bonds connecting family members would be directed to a lower consanguinity demand towards an increase in relationships based on affective and supportive bonds. From this perspective, this study aimed to investigate siblings' universe within new family configurations, from teenagers' perspective. Six teenagers participated in the research, being fifteen to eighteen years old, living in single parent families or step-families, who had half blood siblings or step siblings. 
The qualitative content analysis of the interviews indicated the importance of close interaction among siblings to the sense of siblinghood. Furthermore, the relationship established with the common parent or stepfather/mother has been identified by the teenagers as an important factor for the acknowledgement and for the quality of the siblings' relationship. The sibling bond was ultimately defined by the emotional connections experienced among family members, considering close interaction, support and affective exchanges as necessary items.

Keywords: Siblings. Remarried family. Monoparental family.

\section{Introducãa}

Quando se fala em família, cada vez mais fica difícil imaginar uma forma de sua constituição que possa servir como modelo geral em nossa sociedade. Tem-se mesmo pensado que talvez esse termo não seja passível de uma conceituação comum, mas apenas de descrições de suas possíveis e múltiplas formas de apresentação.

Família e sociedade têm sempre andado lado a lado. Assim, conforme a sociedade sofre alterações (políticas, econômicas, demográficas, culturais, morais, éticas...), estas são sentidas também nas famílias, que, por sua vez, apresentam-se como fonte de mudança social. Ao entrar em contato com diversas famílias, chama atenção o quanto a família de hoje não responde mais ao que, há apenas algumas décadas, se propunha como novo: o modelo nuclear. Atualmente, famílias monoparentais, famílias reconstituídas e famílias homoafetivas constituem a realidade de uma parcela significativa da população. Diante disso, a Psicologia precisa atentar para não cair em pré-concepções e, mais que isso, investigar as novas formas de vínculos aí desenvolvidos, para proporcionar-lhes um olhar renovado. Disso depende, em parte, a possibilidade de se oferecer um trabalho que respeite as diferenças e a dignidade humana.

Neste sentido, o presente estudo partiu do desejo em aproximar-se desses novos arranjos familiares, enfocando, de modo especial, as famílias nas quais existe alguma forma de relacionamento fraterno que não o 'tradicional' laço de irmãos consanguíneos - fator de incremento da complexidade do sistema. Esta pesquisa investigou, então, as novas configurações familiares nas quais, além do padrasto ou madrasta, os filhos passam a conviver com um novo irmão, o qual pode apresentar-se basicamente de duas formas: vir 'pronto', de um relacionamento anterior do padrasto ou da madrasta (irmão 'político' ou 'circunstancial') ou, ser gerado no novo relacionamento de um de seus progenitores (meio-irmão).

Para fins do presente estudo, cabe esclarecer que se considera como 'novas configurações/arranjos familiares' tanto famílias monoparentais, em que apenas um dos progenitores (mãe ou pai) vive com os filhos (Goldani, 1994; Ferreira, 2001; Wagner \& Levandowski, 2008); quanto famílias reconstituídas, ou seja, aquelas em que, após uma separação (oficial ou não oficialmente) de seus primeiros cônjuges, estabelece-se uma nova relação conjugal, a qual se mantém atualmente, na companhia dos filhos do primeiro casamento (Wagner, Falcke \& Meza, 1997; Wagner, 2002; Grisard Filho, 2003).

\section{A familia na atualidade: novas perspectivas}

A partir da década de 1990, como ressalta Goldani (1994), deu-se uma grande diversificação com relação ao modelo privatizado nuclear da família conjugal. Com o incremento das taxas de separação e divórcio, e o consequente aumento do número de famílias monoparentais ou reconstituídas, somadas às melhorias de saúde e extensão da longevidade, produziu-se um aumento na complexidade da vida familiar. Para Moraes (1994), a crise da família nuclear contemporânea no Ocidente esteve vinculada ao enfraquecimento do paradigma católico de vida familiar calcado no matrimônio indissolúvel e no consequente aumento do número de famílias desfeitas e reconstituídas. 0 casamento passou a ser visto como opcional e provisório.

O número de divórcios, aprovado no Brasil em 1977, mais do que dobrou entre as décadas de 1950 e 1990. Além disso, a coabitação como alternativa ao casamento torna-se, numericamente, cada vez mais expressiva e aceita legal e socialmente. Segundo dados do IBGE e PNADs (Ferreira, 2001), referentes à 
demografia brasileira dos anos 1970 a 1995, nota-se que, apesar de a família nuclear - casal com ou sem filhos - continuar representando a maioria dos arranjos domésticos (67\%-1970 e 63\%-1995), houve um crescimento significativo de famílias monoparentais - mãe ou pai com filhos - (10\%-1970 e 18\%1995), assim como aumentou o número de pessoas morando sozinhas (6\%-1970 e 8\%-1995). Paralelamente, houve uma diminuição no número de famílias abrangentes - família conjugal + parentes + agregados - (12\%-1970 e 8\%-1995).

Com isso, as relações entre os membros familiares também se alteraram, redefinindo-se os padrões de hierarquia e sociabilidade. Os filhos e esposa passaram a participar mais intensamente das responsabilidades da família, do mundo do trabalho e da renda familiar. Destaca-se a importante mudança no papel da mulher na sociedade, o qual passou a não mais, necessariamente, estar vinculado à maternidade e ao casamento, e cada vez mais enfatiza seu acesso à esfera pública. A nova colocação da mulher na família se mostrou fundamental para as alterações vividas no âmbito familiar (Moraes, 1994).

Perante tais mudanças, ao analisar os diversos modelos de família, Rossato (1995) propôs a emergência, em nossa sociedade, de uma família que não mais responderia ao modelo nuclear. Essa família nuclear, que nos anos 1960 parecia representar uma organização familiar que, assim como a família patriarcal, perduraria e se expandiria a todas as sociedades, começou a ser questionada apenas quatro décadas após. Estaria emergindo um modelo fortemente centrado na pessoa, com a mínima valorização dos papéis sociais. Segundo os autores, este parece ser um fenômeno iniciado nos países desenvolvidos que se difundiu para os demais países, em especial nas camadas médias da sociedade.

Segundo Valois (1993), na década de 1990, a vida familiar brasileira oscilava entre duas vertentes com relação ao casamento: a primeira, vinculada ao modelo tradicional, tinha na progenitura seu projeto central; a segunda, por sua vez, excluía os filhos do foco, acentuando a individualidade dos cônjuges. No modelo emergente haveria, então, uma ênfase na realização pessoal, mantendo-se o respeito aos limites individuais e à igualdade. 0 casamento passou a ser pensado como uma aliança não mais indissolúvel, mas opcional e provisória. Além disso, em contrapartida ao modelo tradicional de família, numerosa e com papéis claramente distintos (marido provedor e mulher dona de casa e mãe), as famílias atuais caracterizam-se por serem pequenas e com as funções maternas e paternas indefinidas.

A implantação do novo Código Civil, no ano de 2003, apareceu como resultado destas mudanças que, nas últimas décadas, vêm se fazendo presentes na forma de se pensar e organizar as famílias, em especial no que diz respeito aos papéis paternos e maternos. Destacam-se algumas leis importantes do novo Código Civil: o casamento religioso foi regularizado com efeito civil; a união estável passou a ser reconhecida, desde que a relação seja duradoura e contínua; aboliu-se a expressão 'filho legítimo', passando o natural e o adotivo a ter o mesmo tratamento; as mães solteiras passaram a formar família com os filhos; a mãe solteira passou a ser chefe da chamada entidade familiar, assim como todas as demais também passaram a ter o mesmo status (igualdade entre cônjuges); o marido pode usar o sobrenome da mulher e vice-versa, como também a ex-esposa pode manter o sobrenome do ex-cônjuge; a guarda dos filhos pode ficar com o pai ou a mãe, sendo escolhido aquele que reunir melhores condições para isso; marido também pode exigir pensão alimentícia (Minussi, 2003).

A partir das considerações anteriores, notam-se rápidas e importantes mudanças no bojo das famílias, parecendo indicar um momento de transição. Neste contexto, pode-se esperar que a família continue servindo como fonte primária de apoio ao ser humano. Contudo os laços que unem seus membros estariam caminhando para uma menor exigência de consanguinidade em nome de um incremento das relações a partir de laços afetivos de apoio mútuo.

Com base no referido, pode-se inferir que a família está redefinindo o seu modelo, ao menos em uma parte significativa do Ocidente e em algumas categorias sociais identificáveis. Parece que o modelo que se pode esperar se mostra muito mais amplo e abrangente que o existente até o momento (Oliveira et al., 2008; Roudinesco, 2003; Wagner \& Levandowski, 2008). Cabe, então, procurar compreender como estão se processando os relacionamentos interpessoais e afetivos no interior desta família em contínuo processo de mudança. Destaca-se também a importância de uma nova compreensão das relações familiares com relação ao cuidado com os filhos, pois, uma vez que se finaliza a relação conjugal no divórcio, as relações parentais devem se manter indissolúveis às relações parentais (Brito, 2007). 


\section{Separação/divórcio: Reconstituição familiar}

Perpassando os diversos desequilíbrios que fazem parte do desenvolvimento e crescimento da família, poderá haver momentos de crise mais intensa, que venham a pôr em questão a validade da manutenção do relacionamento conjugal. Em tais circunstâncias, uma resolução cada vez mais aceita e frequente em nossa sociedade é a separação do casal e o divórcio.

De acordo com Grzybowski (2002, p. 40): “Como toda crise, repentina ou não, o divórcio é um momento de grandes transformações, que geralmente culminam numa reorganização, seja de caráter singular (famílias monoparentais) ou conjugal (famílias reconstituídas/recasadas)". Contudo até que uma nova reorganização seja alcançada, todos os membros do grupo familiar precisarão reajustar seus papéis e relações, reestruturando este sistema tarefa que não necessariamente será de fácil realização. Para a superação do profundo desequilíbrio resultante do divórcio será necessário, também, que se elabore o luto pela perda da família intacta, renunciando à fantasia de voltarem a ficar juntos (Grzybowski, 2002).

0 aumento do número de separações pode levar a um questionamento da relevância do casamento como instituição social. Entretanto, segundo Féres-Carneiro (2002), seria justamente por valorizarem intensamente o casamento e a relação conjugal que muitos casais, na atualidade, renunciam a uma vida conjugal que não responda as suas expectativas. Assim, na busca por um relacionamento mais próximo aos seus anseios, após uma separação, uma das possibilidades é que os cônjuges venham a constituir uma nova família. Sendo assim, o recasamento, fenômeno cada vez mais frequente, constitui-se em uma possibilidade de reconquistar vínculos essenciais de intimidade, afeto e companheirismo. Conforme Cerveny e Berthould (1997), tais uniões não só revolucionaram as formas de estar ou ser 'casado', como também proporcionaram o aparecimento de novos arranjos familiares.

Os novos arranjos caracterizam-se por uma maior complexidade de papéis e de organização, o que não significa que o processo de uma família reconstituída seja, obrigatoriamente, conflituoso. Os remanejos necessários são possíveis graças à flexibilidade das relações presentes no núcleo familiar (Grisard Filho, 2003; Wagner, Ribeiro, Arteche \&
Bornholdt, 1999). Contudo essa etapa de transição para um novo modelo familiar irá demandar tempo (Wagner, 2002). Estima-se que os indivíduos envolvidos no processo de separação precisem, em média, de dois a quatro anos para reorganizarem suas vidas e elaborarem as principais questões ligadas à separação (Souza, 2000).

Os termos recentemente inventados para descrever as novas uniões após a separação conjugal - famílias 're-feitas', 're-constituídas', 're-casadas' - parecem denotar um processo de repetição, recomeço. Isso condiz, de certa forma, com um primeiro movimento, bastante comum nessas famílias, de buscar nos padrões já conhecidos de suas famílias anteriores os moldes para o funcionamento atual. Entretanto, ultrapassando essa etapa, muitas famílias serão capazes de, progressivamente, criar uma nova identidade familiar própria e mais condizente com o arranjo familiar em que se encontram. Os casos bem sucedidos, o recasamento poderá, então, ser pensado mais como 're-investimento' do que repetição (Wagner, 2002).

Com a separação, a desacomodação e a reestruturação familiar são inevitáveis, assim como o estresse que as acompanha. Novos subsistemas e novos papéis precisarão se desenvolver. 0 que, até então, era uma unidade dos progenitores e filhos, se torna uma unidade de apenas um dos progenitores (e talvez seu novo parceiro) e seus filhos. No caso de haver a entrada de um novo membro no grupo familiar, apesar da tendência de manter-se o padrão de relacionamento anterior, será necessário que, assim como o novo membro se adapte a algumas regras de funcionamento do sistema antigo, este sistema também possa se modificar para incluí-lo (Minuchin, 1982).

Os novos papéis surgidos das famílias recasadas trazem consigo a necessidade de denominações que os abarquem. Contudo parece haver uma inadequação dos termos que se dispõe no momento. Isso fica evidente quando se percebe a criação, pelos filhos, de neologismos como: 'boadrasta', 'mãedrasta', 'mãe-cover', 'paidrasto', 'pai-cover', entre outros. Alguns ainda os tratam como 'tio(a)', ou, não conseguindo estabelecer um vínculo direto com estes, os chamam de 'a namorada/mulher do pai' ou 'o namorado/marido da mãe'. Tal empreendimento denota uma tentativa de superar a conotação negativa dos termos 'madrasta' e 'padrasto', uma vez que essas crianças e jovens estabelecem relações positivas e afetuosas com tais figuras (Grisard Filho, 2003; Wagner, 2002). 


\section{0 relacionamento fraterno}

Apesar do pouco investimento em estudos no âmbito da relação entre irmãos, o tema é complexo e rico, abarcando diversas interações em seu desenvolvimento (Perez, 2002). Inaugurado com a chegada do segundo filho à família, o subsistema fraterno exercerá um grande impacto em seus membros, em especial, no que se refere aos relacionamentos sociais, podendo ser pensado como 'laboratório das interações sociais do sujeito' (Silveira, 2002). Minuchin (1982, p. 63) ressaltou que "no mundo dos irmãos as crianças aprendem a negociar, cooperar e competir". Tal relacionamento apresenta como peculiaridades sua indissolubilidade (nunca se deixa de ser irmão) e o fato de ser, provavelmente, o laço familiar mais duradouro, uma vez que, em geral, nossos progenitores vêm a falecer antes que nossos irmãos.

Como todas as relações familiares, o laço fraterno passará por mudanças ao longo dos ciclos da vida. Durante a infância, a relação apresenta sua fase de formação e fortalecimento; na adolescência, há o auge dos conflitos e das transformações; na vida adulta e na velhice, reequilibra-se. Na adolescência, os irmãos procuram-se, em especial, para conversar a respeito de questões sobre as quais têm dificuldade de falar com os progenitores; já na idade adulta, se estabelece uma relação de amizade, fazendo-os sentirem-se mais próximos. Características que haviam declinado na adolescência, tais como cooperação, confiança, compreensão e companheirismo, tendem, então, a se desenvolver novamente (Silveira, 2002).

A forma como a família cria espaço para um novo bebê, o lugar que a criança vem a ocupar na constelação familiar, é fortemente determinado pela sua relação com seus irmãos. 0 fato de ser o mais velho ou o mais novo, o papel que a ele é destinado e o papel que a criança vem a assumir na família influenciarão seus relacionamentos futuros, marcando o indivíduo para sua vida. Ora: "O amor e a admiração, ou o ressentimento e a inveja dos irmãos afetarão de maneira incisiva cada criança" (Pincus \& Dare, 1981, p. 64).

\section{Os irmãos e a separação-reconstituição familiar}

Diante da separação conjugal, com a instabilidade da estrutura familiar e o desligamento dos progenitores, o relacionamento entre os irmãos pode se apresentar como fonte de apoio aos filhos. Uma estratégia do sistema para lidar com esse período de maior tensão é percebida quando se verifica uma intensificação na coesão do subsistema fraterno (Souza, 2000; Silveira, 2002; Wagner, 2002). A este respeito, Silveira (2002, p. 109) destaca que:

No caso do divórcio e/ou da viuvez, a proximidade emocional tende a aumentar, assim como a frequência do contato e os comportamentos de ajuda. Igualmente, os irmãos costumam aproximar-se em outras situações de iminência de uma perda ou quando esta acontece realmente.

Isso é corroborado pela constatação de que os adolescentes provenientes de famílias reconstituídas tenderiam a relatar relacionamentos mais próximos e íntimos com seus irmãos que aqueles de famílias intactas. Enquanto, nos núcleos familiares intactos, os irmãos mantêm uma relação clássica de rivalidade e competição, nos núcleos reconstituídos haveria um clima de maior cooperação e companheirismo entre eles (Wagner, 2002).

Ao abordar-se o relacionamento fraterno nas famílias reconstituídas, deve-se lembrar que, nesses casos, este subsistema pode apresentar-se com algumas peculiaridades, conforme o arranjo em questão. Pode-se ter, então: irmãos consanguíneos (de pai e mãe - 46\%), meios-irmãos (só por parte de pai $11 \%$, ou de mãe - 24\%), e 'irmãos políticos' (sem laço consanguíneo, filhos do padrasto ou da madrasta com quem coabitam - 18\%) (Wagner, 2002) - a este último caso, Osório (2002) denominou 'irmãos circunstanciais'. Ao ampliar esse espectro, Cicirelli (apud Silveira 2002) propôs a categoria de 'irmãos fictícios', ou seja, "aquelas pessoas que convivem tão intensamente que são como irmãos, mas não possuem vínculo de sangue" (Silveira, 2002, p. 95).

Nos núcleos refeitos, a composição familiar nem sempre fica clara, tanto (e principalmente) para aqueles que procuram compreendê-la desde um olhar externo, quanto para seus membros. Neste tocante, a partir dos desenhos de suas famílias realizados por adolescentes de famílias recasadas, Wagner (2002) identificou que a maioria deles (75\%) integrou os novos membros (padrasto, madrasta e filhos destes) à sua percepção de família. Nessa delimitação de suas famílias, observou-se que os adolescentes consideraram da família aqueles membros com os quais coabitam, em especial quando viviam com estes a mais de dois anos. Assim, percebe-se 
que, além da consanguinidade, é a variável coabitação que tem norteado a definição dos novos arranjos familiares nos núcleos reconstituídos.

\section{Método}

O presente estudo visou a uma aproximação do universo dos irmãos nas novas configurações familiares a partir do olhar dos filhos adolescentes. Assim, buscando apreender as representações e significados vinculados a esta vivência, optou-se por uma abordagem qualitativa de pesquisa.

Participaram da pesquisa seis adolescentes quatro do sexo feminino e dois do sexo masculino com idades entre 15 e 18 anos, estudantes do segundo ou terceiro ano do ensino médio que viviam em famílias monoparentais ou reconstituídas e possuíam meios-irmãos e/ou irmãos políticos/circunstanciais (filhos do padrasto ou madrasta).

A pesquisa realizou-se junto a uma instituição pública de nsino Médio de uma cidade do interior do Rio Grande do Sul (RS). Após aprovação da direção da escola, a apresentação da pesquisa e o convite aos alunos foi realizado em sala de aula. Os alunos que correspondiam ao universo da pesquisa e que concordaram em participar assinaram o Termo de Consentimento Livre e Esclarecido e responderam a uma entrevista individual semiestruturadas (Gaskell, 2002; Turato, 2003). As entrevistas foram realizadas em um único encontro, com duração média de trinta minutos. Todas as entrevistas foram gravadas, sob autorização, e transcritas na íntegra para registro dos dados. A partir das entrevistas, procurou-se contemplar os seguintes eixos norteadores: a história familiar; mudanças advindas da 'nova família'; relacionamento com os progenitores e padrasto/ madrasta (quando houvesse); relacionamento com irmãos (irmão consanguíneo, meio-irmão, irmão político); diferenças no relacionamento com irmãos de diferentes graus de parentesco; preocupações, ansiedades, expectativas com relação à família atual.

\section{Resultados e discussão}

Realizou-se uma análise qualitativa dos dados por meio da técnica de análise de conteúdo (Bardin, 1977). Visando a descrever tendências presentes no conteúdo das comunicações, as falas dos entrevistados foram agrupadas a posteriori em quatro categorias de análise: cuidado e carinho; meios-irmãos; irmãos políticos/circunstanciais; irmãos fictícios.

\section{Cuidado e carinho}

Em consonância ao referido por Perez (2002) a respeito do filho mais velho, nota-se o quanto este assumiu, junto aos irmãos, uma função de cuidados e responsabilidade. Isso poderia estar ampliado nessas famílias em virtude do distanciamento do pai e ao maior envolvimento dos filhos nas responsabilidades domésticas. A este respeito, em estudo realizado com jovens adultos, Brito (2007) ressaltou a tendência de um afastamento do pai no processo de separação, uma vez que, na maior parte dos casos, a guarda dos filhos fica com a mãe. Diante desta realidade, segundo a autora, criam-se lacunas e fragilidades que levariam os filhos a assumirem a função de cuidadores de seus irmãos.

Assim, o irmão mais velho passaria a desempenhar até mesmo tarefas de seus progenitores junto aos irmãos.

Eu sou uma mãe pra minha irmã, porque a minha mãe trabalha o dia inteiro, né. Aí, eu agora vou pra casa, vou tirar ela da cama, vou arrumar a cama, vou dá banho, vou arrumar pro colégio, vou mudar, vou dar o lanche da manhã pra ela, vou dar almoço. Aí eu vou pro colégio. Aí eu saio do colégio, eu vou pegar ela ou quando ela tem aula de música ou um dia de dança, tem que levar isso, tem que levar aquilo. Chega em casa, fazer temas. Vou fazer temas com ela, vou dar banho nela, pra deixar ela brincar, pra eu fazer as minhas coisas" (Adolesc. 1 - fem., 16 anos);

Eles vão lá pra casa, me ajudam. Porque a minha mãe trabalha, então quem faz comida, limpa a casa, é tudo eu. E eles me ajudavam. Daí tinha aquele horário: 'Vocês me ajudam, tal horário vocês jogam videogame. Vocês me ajudam, tal horário vocês brincam na piscina.' E assim ia (Adolesc. 2 - fem. , 16 anos).

O irmão mais velho assume tarefas educativas para com os mais novos, mesmo que nem sempre se sinta apto a desempenhar este papel.

Eu tento cuidar, tento educar ela, porque a minha mãe não tem tanto tempo. Então, eu digo: 'Luiza, tu vai sair na casa dos outros e tu vai fazer isso?', 'Não vou. Não vou.' Daí a gente briga, eu me estresso. Aí eu me estresso, me 
revolto com ela. Depois eu vou lá e peço desculpas. Se eu brigo, eu vejo que ela me olha com um olhão arregalado. Aí depois eu tento consertar (Adolesc. 1 - fem., 16 anos).

O irmão mais velho assume o mais novo como sua responsabilidade, passando a sentir-se com maiores direitos sobre este, inclusive em relação à mãe. Já que a ele cabe cuidar e, às vezes, educar o irmão, coloca os progenitores em uma posição de menor poder sobre este.

Eu não sei porque eu tô sempre brigando com ela. Eu quero que ela faça as coisas, e ela é muito teimosa, ela é muito arteira. Então, eu quero que ela faça as coisas. E a gente briga, briga, briga, briga. Mas eu não admito que a minha mãe brigue com ela. Eu não admito. Eu brigo, xingo ela, tenho vontade de esganar ela, mas eu não admito que a minha mãe brigue com ela (Adolesc. 1 - fem., 16 anos).

Contudo sente-se sobrecarregado em alguns momentos. "Mas eu quero continuar cuidando da minha irmã, só que com um pouquinho de folga" (Adolesc. 1 - fem., 16 anos).

Pelo contato diário com o irmão e a relação de cuidado, vem se estabelecer um forte sentimento de proteção do irmão mais novo. Isso parece vincular-se também à identificação existente entre eles, uma vez que o mais velho percebe que o irmão sofre com situações pelas quais ele já passou e hoje consegue lidar de forma mais madura. Procura, então, preservar o irmão do sofrimento, por compreender identificatoriamente suas vivências.

O pai da minha irmã, agora que ela liga pra ele, ele trata ela áspero. Eu fico furiosa com ele. Eu tenho vontade de pegar o telefone e botar a boca nele. Porque eu sei o que ela tá sentindo, aquela vontade de ter um pai, sabe, de conversar com ele. Eu sei, eu entendo ela, e não posso fazer nada. Eu tento, parece que eu tenho vontade de pegar aqueles sentimentos dela pra mim - porque eu já sofri tudo aquilo - e livrar ela disso (Adolesc. 1 - fem., 16 anos);

Daí agora tem a Camila [irmã por parte de mãe] com quatro meses, que foi resultado dum namoro da minha mãe de dois anos. Quando ela ficou grávida, ela não queria. Daí eu peguei e insisti pra ela ficar. Daí, acabou nascendo agora. [...] É que eu acho que se fosse comigo eu ficaria. Eu sou totalmente contra tu matar uma criança antes dela nascer. E, eu sei lá, eu tinha quinze anos já, podia entender, podia ajudar ela. Aí eu resolvi, e fiz a cabeça dela até ela ficar (Adolesc. 3 - fem., 15 anos).

Assim, os relatos corroboram a ideia de que os irmãos de famílias reconstituídas ou monoparentais desenvolveriam entre si uma relação mais próxima de apoio e proteção, como forma de melhor lidar com as dificuldades enfrentadas perante às instabilidades familiares (Wagner, 2002).

\section{Meios-irmãos}

Referente à relação entre meios-irmãos, percebe-se um forte vínculo de carinho, em que o fato de possuírem apenas um dos progenitores em comum não altera o sentimento entre eles:

E eu tenho essa ligação com a minha irmã. Eu amo minha irmã como se ela fosse filha do meu pai, sendo ou não. Eu amo minha irmã desse jeito assim. Não interessa se ela é filha de outro (Adolesc. 1 - fem., 16 anos).

Isso, contudo, se limita aos casos em que a convivência com este irmão foi possível e, em especial, quando se manteve um relacionamento positivo com o genitor comum. Assim, a convivência é tomada como fator marcante para o estabelecimento da relação e do sentimento fraterno.

Eu considero ela como irmã e as outras não, pelo fato de eu conviver mais. Desde que ela nasceu, eu sempre convivi com ela. Na hora que eu fui morar com a vó ela foi também. E a gente sempre esteve junto (Adolesc. 6 fem., 18 anos);

Já por eu não ter tanto contato com ele, eu não sei se eu teria tanta ligação assim. Lógico que eu queria conhecer e ia me dar super bem, mas não sei se eu ia sentir aquela coisa de dentro, sabe, de irmãos, como eu sinto com a minha irmã (Adolesc. 1 - fem., 16 anos).

Neste ponto, é interessante notar que a mãe, por ser a presença mais constante na vida dos filhos (Rizzini, 2001), passa a ser considerada como um maior elo de ligação entre os irmãos que o pai. Assim, haveria uma tendência a se desenvolver um sentimento fraterno mais forte entre irmãos por parte de mãe do que aquele estabelecido com os irmãos por parte de pai. Dentre os participantes deste estudo, alguns adolescentes associara esta maior ligação com 
o irmão por parte de mãe a uma questão biológica, por terem sido gerados no mesmo 'lugar'. 0 fato de carregar o bebê na barriga por nove meses, então, colocaria a mãe numa posição de maior participação na constituição da criança do que o pai.

É meio estranho, porque se é só filho da mesma mãe, a gente saiu, digamos assim, do mesmo lugar. Agora filhos de pai, parece tão longe a ligação. Eu acho mais longe a ligação filhos do mesmo pai do que da mesma mãe. Não sei se mãe e filho tem um elo maior, uma ligação maior (Adolesc. 1 - fem., 16 anos);

Olha, até por eu não ter pai, eu ignoro o pai dela. É minha irmã, filha da minha mãe. Não me interessa o pai. É minha irmã porque é filha da minha mãe. Eu gosto dela igual. Ah, é a minha cara! Então, pai tu não tem, é irmã porque é filha da minha mãe. Não interessa. Fez sozinha! (Adolesc. 3 - fem., 15 anos).

Por não haver um convívio desde cedo, a relação com o irmão por parte de pai nem sempre é sentida como natural. É difícil sentir-se como irmão.

Coisa que eu não consigo é ver me chamarem de mano. Sempre sozinho, filho único, quando chamam de mano, assim. O namorado da minha irmã, mesmo, chama de cunhado. Não entra na minha cabeça direito. Acostumado sempre sozinho, sempre ver os meus primos por parte de mãe chamando o outro: 'Ah, mano, não sei o quê. Cunhado.' Comigo eu sinto diferente. Parece que é diferente comigo (Adolesc. 4 - masc., 17 anos).

É interessante notar o quanto a relação com o irmão esteve intermediada pela relação progenitor comum. Nos casos em que o pai foi percebido como desinteressado pelo filho, quando havia ressentimento na relação com ele, isso se transferiu para a relação com os irmãos - filhos deste.

Eu não considero ele meu pai. Não sinto assim, um amor de pai, sabe. Ah, é da minha família, fazer o quê. Eu tenho uma irmã que tem 7 anos. Também não convivo com ela, não gosto dela, ela não gosta de mim (Adolesc. 2 - fem. , 16 anos);

Na mensagem dos meus 15 anos o meu tio leu um negócio e eu não botei o nome dela. Só botei: 'Filha de Fernanda, de Nilo e irmã de Fabiano [irmão consanguíneo]. E não botei o nome da minha irmã [por parte de pai]. Ele ficou magoado e eu não fiquei. Disse pra ele que eu não ia me sentir bem, porque eu não considero ela minha irmã (Adolesc. 2 - fem., 16 anos).

Além do convívio e do relacionamento com o genitor, os adolescentes ressaltaram a ligação de sangue como algo importante para o sentimento fraternal. Por mais que o elo se dê por meio de apenas um dos progenitores, a consanguinidade estaria associada à ideia de compromisso e proteção. Mesmo que não haja tanto contato e amizade, o fato de compartilharem o 'sangue' os coloca numa posição diferente de simples amigos, na posição daquele com quem se pode contar.

Não é aquele negócio de ser grudado. Mas é um carinho mais que a gente tem, porque é meu irmão, é uma parte, mesmo sangue, né. Então, é esse carinho mais que a gente tem um pelo outro. [...] A gente tem mais aquele negócio de irmão de sangue, sabe. É um o sangue do outro ali. O que um precisar do outro tá ali. Só que esse negócio de compartilhar coisa, isso a gente não tem muito. Daí, eu tenho amigos (Adolesc. 5 - masc., 16 anos).

Os participantes relataram também a estranheza e mesmo tensão, ao conhecer os irmãos (meios-irmãos). Possuem a informação de que são irmãos, o que pressupõe uma relação íntima, contudo não se percebem como possuindo intimidade e proximidade com eles. Além disso, identificou-se o receio de não ser aceito ou não ser bem recebido pelos novos irmãos.

A minha mãe sabia tudo, só que ela nunca me falava. Aí, um dia na catequese ela viu o Douglas, meu irmão, e aí nos conhecemos, nos apresentamos. (...) Aí a gente ficou naquele negócio, nos damos um abraço. Bah, agora que a gente se dá super bem, conversamos um monte (Adolesc. 5 - masc., 16 anos);

Ih, eu imaginei várias coisas: será que eu não fui bem aceito, será que ela não gosta de mim? Como é que será eu chegar na família dela agora? Acho que ela nunca soube que que ele tinha outro filho. Aí eu ficava pensando. Mas depois foi tudo bem (Adolesc. 4 - masc., 17 anos).

\section{Irmãos políticos/circunstanciais}

Quando o padrasto é considerado como pai, seus filhos, consequentemente, passam a ser considerados como irmãos dos adolescentes. Nesses casos, mais que em qualquer outro, o que une os irmãos é fundamentalmente o afeto, além, é claro, de um convívio necessário. "Eu acho que não precisa ser de 
sangue. $O$ que vale é o coração. E eu gosto deles, acho eles um amor" (Adolesc. 2 - fem., 16 anos).

Nos casos em que havia pouco contato com o pai biológico e sentimentos de ressentimento do filho para com este, os irmãos por parte do padrasto possuíam um maior status de irmão que os meios-irmãos por parte de pai. 0 laço afetivo, nesses casos, superaria o laço de sangue.

Considero eles meus irmãos. Digo: 'Ah, minha irmã vai vir aqui hoje. Vou trazer a minha irmã.' E levo junto. Agora a minha irmã, a outra, de sangue, por parte de pai, não. Porque eu, nunca convivi com o meu pai (Adolesc. 2 - fem. , 16 anos);

A minha mãe casou de novo e o meu padrasto tem dois fiIhos, um de oito e a outra de doze. E com eles eu me dou super bem. Eles vieram agora, eles ficaram comigo no meu quarto. Tenho prazer de cuidar deles. Agora, de minha irmã nem faço questão de ver (Adolesc. 2 - fem., 16 anos).

Assim como acontece com os irmãos por parte de pai, os adolescentes indicaram também sentir-se um pouco confusos ao conhecer um irmão por parte do padrasto. Não haveria a intimidade de irmãos que convivem entre si.

E a Amanda [irmã por parte do padrasto] vai ficar no quarto da Vitória [irmã por parte de mãe]. E eu e a Vitória, a gente se empresta roupa. Eu gosto do espelho do quarto dela. Eu vou lá, entro no quarto dela a hora que quero. Daí eu perguntei para a mãe: 'E agora, como eu vou entrar no quarto da Vitória, se nem é mais quarto dela?' Aí ela disse que iria ser normal: 'É tua irmã.' Mas fica meio assim. 'E agora? Entro ou não entro? Peço licença ou entro direto?' Fica aquela coisa assim. Agora, até se acostumar, vai um tempo (Adolesc. 6 - fem., 18 anos).

Nesses casos, identifica-se claramente a necessidade de adaptação quando da entrada de um novo membro no arranjo familiar. Nesse momento, há uma tendência de preservação da ordem de funcionamento vigente, ao mesmo tempo em que se abre espaço às características e peculiaridades trazidas pelo novo indivíduo (Minuchin, 1982):

Acho que não vai mudar muito. Ela [filha do padrasto] vai ter que se habituar. Como a minha mãe diz, ela vai ter que se habituar com as nossas regras. Cada casa tem uma regra, tem uma maneira de fazer as coisas. Nenhuma vai ser igual à outra. Agora, não vai ser nós que vamos nos habituar a ela. Ela está chegando. Ela vai se adaptar à nossa rotina, ao jeito com que a gente faz as coisas. Lógico que a gente pode aceitar as coisas dela, como ela vai aceitar as nossas (Adolesc. 6 - fem., 18 anos).

\section{Irmãos fictícios/'primos-irmãos'}

Quando a mãe da família não se casa novamente após o divórcio, haveria uma tendência a buscar mais o apoio de sua família de origem, passando a viver de maneira mais próxima a sua própria mãe, irmãos e sobrinhos. Nesse contexto, os filhos teriam maiores oportunidade de conviver com seus primos, que podem vir a ser considerados como irmãos, especialmente quando habitam a mesma casa.

Eles moravam na mesma casa que nós. É que a casa era grande só pra mim e pra minha mãe, era do meu vô. Eles tavam pagando aluguel, então, eles foram morar conosco. Ele tem mais dois filhos, eles quatro. Então, esses aí passaram a ser meus irmãos. Conviveu tanto (Adolesc. 4 - masc., 17 anos);

Quando eu era pequena, eu fui criada junto com meus dois primos. E eu sempre convivi como irmãos com eles. Até eles morrem de ciúmes quando eu saio. [...] Sempre foi assim, desde pequena. Com eles eu convivo como irmãos (Adolesc. 3 - fem., 15 anos).

Ao longo deste tópico de análise, fica expresso, de maneira marcante, os critérios apontados na pesquisa de Wagner (2002) como parâmetros para a delimitação da categoria de irmãos, quais sejam, a consanguinidade e/ou a coabitação. Contudo a partir dos dados levantados, torna-se relevante ampliar este último parâmetro de forma a incluir não apenas a coabitação, mas também a ideia de convívio, proximidade, além da importante questão do afeto e carinho.

\section{Considerações finais}

Acompanhando as transformações sociais, os novos arranjos familiares constituem-se como uma realidade cada vez mais presente dentre as famílias. Contudo esta é uma questão ainda bastante recente, em especial no Brasil, onde, há apenas três décadas, houve a instituição legal do divórcio. Assim sendo, as novas formas de ser família apresentam inúmeros aspectos ainda não explorados. 
Uma questão importante, advinda com as novas configurações familiares, refere-se à necessidade de se refletir a respeito dos parâmetros que se vem utilizando na delimitação e conceituação de família. Ao aproximar-se dos sujeitos imersos nessas realidades, o que, de um ponto de vista externo, parece confuso e caótico, vai demonstrando suas regularidades e coerências. A complexidade das relações de parentesco, dos papéis assumidos nos grupos familiares, começa a se dissolver no momento em que se deixa de buscar sua compreensão a partir do fio condutor da consanguinidade. Sem deixar de considerar o laço de sangue, nota-se que este, por mais que suficiente para fornecer o grau de parentesco, não o é para o desenvolvimento do sentimento do laço de parentesco. 0 fato de saber quem é seu irmão, não faz com que os adolescentes, necessariamente, o considerem como tal - o que se estende a outros membros da família. 0 que passa, então, a delimitar o vínculo familiar, em última instância, são as ligações afetivas estabelecidas entre os sujeitos. Para tanto, sendo necessários, o convívio, o apoio mútuo, a troca afetiva.

Contrariamente ao que se poderia esperar, as novas formas em que se apresentam as famílias vêm ressaltar a importância das relações nelas estabelecidas, a importância da família como fornecedora de relações humanas significativas. Como um sistema psicossocial, mais que biológico, essas famílias explicitam a relevância das interações internas, do afeto, do cuidado entre si, uma vez que é nisso que se sustentam em grande parte. Pode-se mesmo, pensá-las como uma forma de problematizar a garantia e a automatização dos laços estabelecidos nas famílias nucleares tradicionais.

Diante destas questões, destaca-se que a família continua sendo a fonte primária de apoio do ser humano. No caso das novas configurações familiares, o que, em um primeiro momento, pareceria indicar a uma redução da rede de apoio (famílias monoparentais, separação conjugal), pode vir a delinear-se como uma ampliação deste sistema. 0 desmembramento da família nuclear inicial deixa espaço para que outras figuras venham a contribuir na sustentação do grupo, tais como: membros da família de origem dos progenitores (avó, tios, primos), um novo companheiro da mãe ou do pai, talvez seus filhos, sua ex-mulher, entre outros.

\section{Referências}

Bardin, L. (1977). Análise de conteúdo. (Luís Reto e Augusto Pinheiro Trad.). Lisboa: Edições 70.

Brito, L. M. T. (2007). Família pós-divórcio: A visão dos filhos. Psicologia Ciência e Profissão, 27(1), 32-45.

Cerveny, C. M. O., \& Berthoud, C. M. E. (1997). Família e ciclo vital: Nossa realidade em pesquisa. São Paulo: Casa do Psicólogo.

Féres-Carneiro, T. (2002). Prefácio. In A. Wagner (Org.). Família em cena: Tramas, dramas e transformações. Petrópolis: Vozes.

Ferreira, F. (2001). A família brasileira hoje: Estrutura, dinâmica, distribuição de papéis, demanda por serviços. In M. Tengel. Políticas públicas de apoio sociofamiliar: Curso de capacitação de conselheiros tutelares e municipais (pp. 48-61). Belo Horizonte: Ed. PUC-Minas.

Gaskell, G. (2002). Pesquisa qualitativa com texto, imagem e som: Um manual prático. Petrópolis: Vozes.

Goldani, A. M. (1994). As famílias brasileiras: Mudanças e perspectivas. Cadernos de Pesquisa, (91), 7-22.

Grisard Filho, W. (2003). Famílias reconstituídas: Breve introdução ao estudo. In G. C. Groeninga \& C. R. Pereira (Org.). Direito de Família e Psicanálise: Rumo a uma nova epistemologia (pp. 255-268). Rio de Janeiro: Imago.

Grzybowski, L. (2002). Famílias monoparentais: Mulheres divorciadas chefes de família. In A. Wagner (Org.). Família em cena: Tramas, dramas e transformações. Petrópolis: Vozes.

Minuchin, S. (1982). Famílias: Funcionamento \& tratamento. (Jurema Cunha Trad.). Porto Alegre: Artes Médicas.

Minussi, F. (2003). País Ganha um novo Código Civil. Jornal A Razão, Caderno Geral, 10.

Moraes, M. Q. (1994). Infância e cidadania. Cadernos de Pesquisa, (91), 23-30.

Oliveira, D., Siqueira, A., Dell'Aglio, D., \& Lopes, R. C. S. (2008). Impacto das configurações familiares no desenvolvimento de crianças e adolescentes: Uma revisão da produção científica. Interação, 12(1), 87-98. 
Osório, L. C. (2002). Casais e famílias: Uma visão contemporânea. Porto Alegre: Artmed.

Perez, A. F. (2002). O filho primogênito: Suas características e seus relacionamentos no contexto familiar. In A. Wagner (Coord.). Família em cena: Tramas, dramas e transformações (pp. 113-131). Petrópolis: Vozes.

Pincus, L., \& Dare, C. (1981). Psicodinâmica da família. (Clara Rotenberg e Shirley Kleinke Trad.). Porto Alegre: Artes Médicas.

Rizzini, I. (2001). Crianças, adolescentes e suas bases familiares: Tendências e preocupações globais. In S. G. Sousa \& I. Rizzi (Org.). Desenhos de família: Criando os filhos. A família goianiense e os elos parentais (pp. 23-44). Goiânia: Cânone Editorial.

Rossato, R. (1995). Família: A emergência de um novo modelo? Revista Estudos Leopoldenses, 31(141), 99-118.

Roudinesco, E. (2003). A família em desordem. Rio de Janeiro: J. Zahar.

Silveira, L. (2002). 0 relacionamento fraterno e suas características ao longo do ciclo vital da família. In A. Wagner (Org.). Família em cena: Tramas, dramas e transformações (pp. 93-112). Petrópolis: Vozes.
Souza, M. (2000). Depois que papai e mamãe se separaram: Um relato dos rilhos. Psicologia: Teoria e Pesquisa, 16(3), 203-211.

Turato, E. R. (2003). Tratado da metodologia da pesquisa clínico-qualitativa. Petrópolis: Vozes.

Valois, J. (1993). Sociologie de la famille ou Québec. Anjou: Centre Educatif et Culturel.

Wagner, A., Ribeiro, L. S., Arteche, A. X., \& Bornholdt, E. A. (1999). Configuração familiar e o bem-estar psicológico dos adolescentes. Psicologia: Reflexão e Crítica, 12(1), 147-156.

Wagner, A. (2002). Possibilidades e potencialidades da família. In A. Wagner (Org.). Família em cena: Tramas, dramas e transformações (pp. 23-38). Petrópolis: Vozes.

Wagner, A., Falcke, D., \& Meza, E. (1997). Crenças e valores dos adolescentes acerca de família, casamento, separação e projetos de vida. Psicologia: Reflexão e Crítica, 10(1), 155-167.

Wagner, A., \& Levandowski, D. C. (2008). Sentir-se bem em família: Um desafio frente a diversidade. Texto \& Contexto, 7(1), 88-97. 
